\title{
Determination of aircraft hydraulic system pipeline leak cause
}

\author{
Tatyana Osipok ${ }^{1}$, Semyon Zaides ${ }^{1}$ and Hin Nguyen ${ }^{2}$ \\ ${ }^{1}$ Irkutsk National Research Technical University, Irkutsk, Russia \\ ${ }^{2}$ Shao Do University, Hai Zyong, Vietnam
}

\begin{abstract}
The purpose of this article is to determine the cause of leak of the aircraft hydraulic system pipeline detected during pre-flight flight preparation. Results of spectral analysis of material, mechanical testing, analysis of defect structure by optical fractography and metallographic analysis are presented.
\end{abstract}

\section{Introduction}

Despite the successes in the development of various technologies, the destruction of machine parts, accompanied by material losses and even human lives, is still happening. The accumulation of experience in determining the nature of damage and the causes of its occurrence subsequently contribute to the improvement of the manufacturing processes of parts and control methods, which in turn make it possible to prevent subsequent destruction of this type [1].

Elements of aircraft hydraulic system are subjected to considerable vibration loads during operation, as well as sharp pressure and temperature differences, as a result of which there is a high susceptibility of elements to the formation of various types of defects that lead to malfunctions and failures of the hydraulic system [2-3].

On a research the pipeline from steel $12 \mathrm{X} 18 \mathrm{H} 10 \mathrm{~T}$ with thickness of a wall of $1.2 \mathrm{~mm}$, for the purpose of definition of the reason of the leak found when carrying out preflight preparation of the aircraft arrived.

In order to achieve this goal, it is necessary to carry out: Material Characteristics Analysis; spectral analysis and mechanical testing to establish compliance with material standard requirement; analysis of defect structure by optical fractography method; metallographic analysis of material.

\section{Material and methods of research}

The material grade was determined using an optical emission spectrometer Q4 TASMAN.

Tensile strength is determined by stretching two longitudinal samples in the form of strips cut along the pipe axis (working part width $12.0 \mathrm{~mm}$ ) on a test machine LFM-100 in accordance with the requirements of GOST 10006-80. The test machine automatically draws a stretch diagram showing the functional relationship between stress and strain during static stretching of the sample before it breaks. 
Fractional analysis was performed using a Stemi 2000C stereomicroscope. The photography was done with Nexsys Image Expert.

Preparation of microslips for metallographic studies was carried out according to known techniques [4] on a polishing machine of the PHOENIX model. The metalgraphic research was conducted on the inverted Axio Vert.A1 microscope. Photographing is done using Thixomet PRO.

Cutting of samples of pipeline for examination is performed on abrasive-cutting machine of model AbrasiMet 250 using cooling emulsion, in order to prevent steel overheating.

\section{Results and discussion of the study}

Pipeline material - steel 12X18H10T GOST 19277-73. Stainless steel 12X18H10T belongs to the class of chromium-nickel austenitic steel not hardened by thermal treatment, which has a complex of valuable properties (high ductility, increased corrosion resistance, good processability), which in turn caused its use as a structural material subjected to the combined action of stresses, high temperatures and aggressive media [5-6].

In accordance with the requirements of GOST 19277-73, the chemical composition of steel should comply with the requirements of GOST 5632-72, the mass fraction of titanium should not exceed (C-0,02) 5\%-0.7\%. As a result of chemical analysis, it was found that the material corresponds to steel grade $12 \mathrm{X} 18 \mathrm{H} 10 \mathrm{~T}$ in terms of elemental composition. The chemical composition of steel obtained as a result of the analysis and the requirements of GOST 5632-72 are presented in Table 1.

Table 1. Chemical composition of steel 12X18H10T (\%)

\begin{tabular}{|l|c|c|c|c|c|c|}
\hline & $\mathrm{C}$ & $\mathrm{Cr}$ & $\mathrm{Ni}$ & $\mathrm{Si}$ & $\mathrm{Mn}$ & $\begin{array}{c}\mathrm{Ti} \\
\text { (GOST } \\
\text { Requirements of }\end{array}$ \\
\cline { 2 - 7 } $\begin{array}{l}\text { GOST 5632-72 } \\
\text { no more } \\
0.12\end{array}$ & $\begin{array}{c}17.00- \\
19.00\end{array}$ & $\begin{array}{c}9.00- \\
11.00\end{array}$ & $\begin{array}{c}\text { no more } \\
0.80\end{array}$ & $\begin{array}{c}\text { no more } \\
2.00\end{array}$ & $\begin{array}{c}(\mathrm{C}-0.02) 5 \\
-0.7\end{array}$ \\
\hline $\begin{array}{l}\text { The obtained } \\
\text { data }\end{array}$ & 0.06 & 17.35 & 10.50 & 0.24 & 1.16 & 0.55 \\
\hline
\end{tabular}

Two samples cut from the pipe were subjected to mechanical tensile test to determine the pipeline strength. As a result, the strength of the samples is $627 \mathrm{MPa}$ and $598 \mathrm{MPa}$, which meets the requirements of GOST 19277-73 (at least $549 \mathrm{MPa}$ ).

During visual-optical inspection of the external surface of the pipeline, at the place of leakage, no defects were found. After opening the pipeline along the generatrix, a defect in the form of a locally located cavity in the metal, accompanied by a dark-colored section, extended further along the generatrix, was visually detected in order to obtain a sufficient view for inspection of the inner surface. Length of defects $\sim 20 \mathrm{~mm}$, width $\sim 8 \mathrm{~mm}$. The appearance of the defect is shown in Fig.1a.

To analyze the structure of pipeline defects, the internal surface was examined by optical fractography. As a result of the pipeline study, it was established: the discovered cavity is directed mainly along the generatrix, spreads deep into the metal and has a "porous, spongy" structure; the dark area of the surface around the cavity, found during visual inspection, is pitting lesions with a diameter of up to $1 \mathrm{~mm}$. The photo of defects obtained at magnification of 20x is shown in Fig. $1 \mathrm{~b}$. 


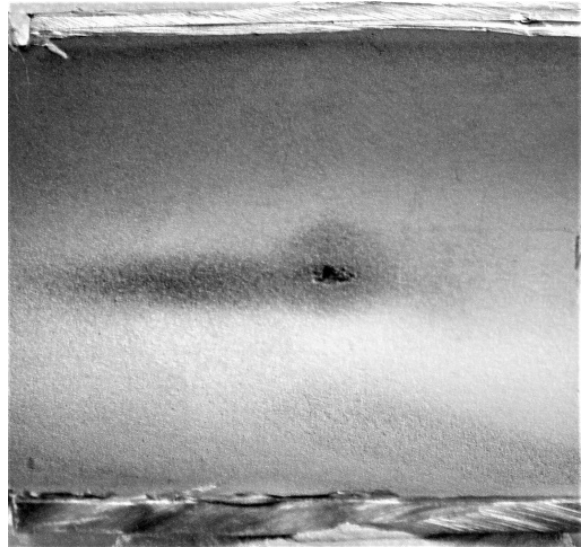

a)

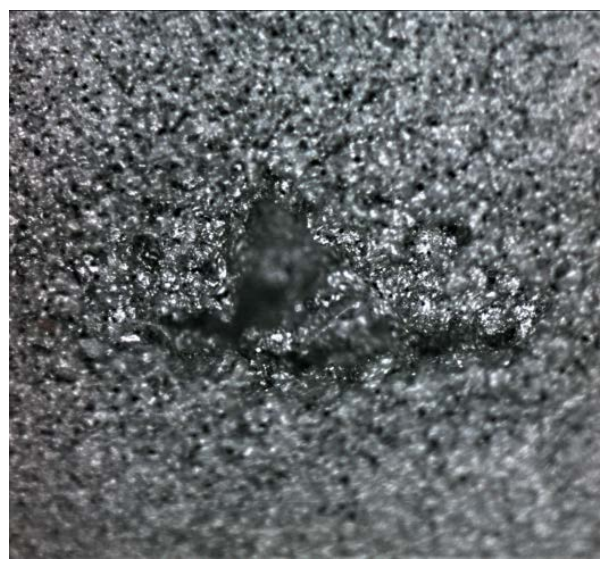

b)

Fig. 1. (a) Appearance of the defect on the inner surface of the pipeline, (b) at increase of 20x.

The presence of damages with a porous, spongy structure is characteristic of cavitation wear that occurs when solids contact liquid. Cavitation is the process of formation of vaporgas bubbles in liquid media, followed by their collapse and the release of a large amount of energy, which is accompanied by hydraulic shocks. The impact of many such microshocks leads to the gradual destruction of nearby solids, the formation of rather deep and complex lesions in the relief. After the appearance of the initial surface damage, the cavitation process is accelerated [7].

Thus, in appearance, the defects are ulcerative corrosion lesions and traces of cavitation wear.

To clarify the nature of the defect, a metallographic study was carried out in transverse microslips. As a result, there are non-metallic inclusions near the defect. Assessment of metal contamination by non-metallic inclusions according to GOST 1778-70 is not possible due to insufficient pipe wall thickness $(1.2 \mathrm{~mm})$ under condition of minimum thickness of 6 $\mathrm{mm}$. Also, traces of plastic deformation in the form of enveloped recesses of deformed austenite grains were found in the microslip of the examined section (Fig. 2), which indicates the presence of mechanical influence.

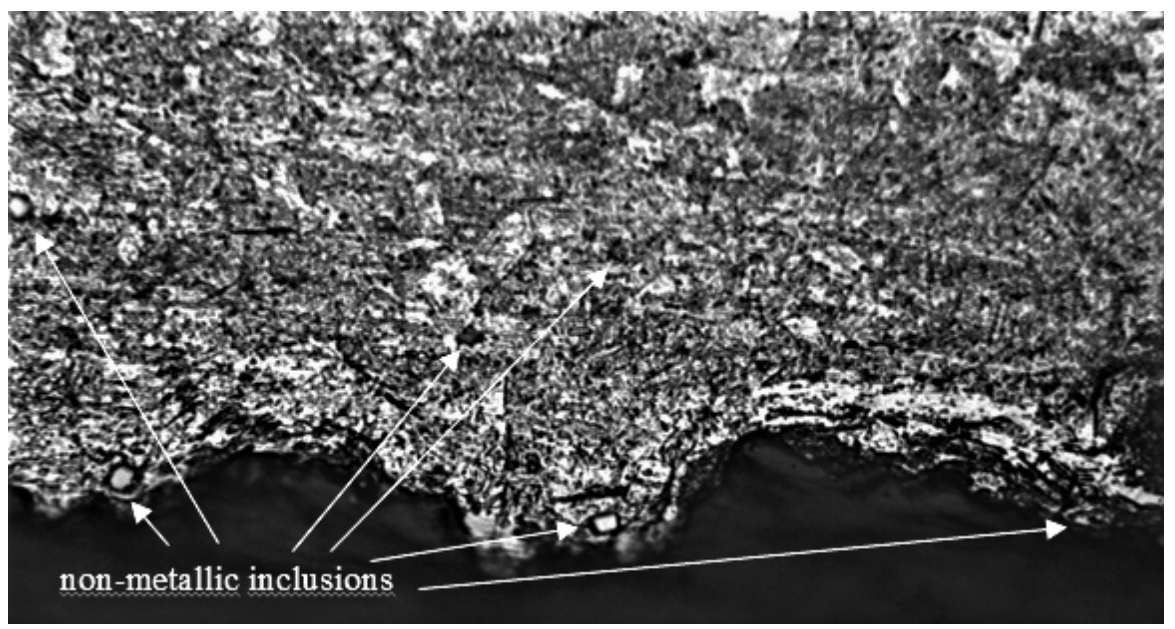

Fig. 2. Microstructure at increase of 500x 
Thus, the sequence of defect formation is as follows. Initially, on the inner surface of the pipeline, point corrosion lesions (pittings) occur at the places of clusters of non-metallic inclusions, then under the influence of the flow of hydraulic fluid, oxide films are removed, which accelerates corrosion processes. Damaged surface undergoes cavitation wear (erosion) due to non-stationary movement of hydraulic fluid. Over time, defects deepen and lead to destruction of the pipeline.

The configuration of defects oriented in the direction of plastic deformation of the material, as well as its nature, indicate that they were formed, obviously, at the places of clusters of lowercase non-metallic inclusions.

\section{Conclusions}

As a result of the study, it was found:

1. Material grade and pipe tensile strength meets the requirements of the material standard.

2. The cause of the pipeline leak is the formation of defects on the internal surface of the pipeline due to the simultaneous corrosion processes and cavitation wear.

\section{References}

1. A. Ilyushchenko, L. Markova, V. Chekan, I. Fomikhina, V. Koleda, Atlas of industrial destruction of various structures (2017)

2. G. Tymoshenko, D. Anishchenko, Promising method of repair of aircraft pipelines with minor operational damage, Materials of the IX All-Russian Scientific and Technical Conference with international participation, p. 149-153 (2019)

3. S. Zides, N. Wolykh, Defects of structural materials, part 2 (2016)

4. A. Anisovich, I. Rumyantseva, Practice of metallographic research of materials (2013)

5. V. Bubnov, S. Marfitsyn, Austenitic steels and plastic deformation, Bulletin of Kurgan State University, 2, p. 41-43 (2014)

6. G. Snezhnoy, On the possibility of controlling small deformations of austenitic chromium-nickel steels by magnetometric method, Aerospace engineering and technology, 9, p. 131-135 (2010)

7. I. Bogachev, Cavitation destruction and cavitation-resistant alloys (1972) 